\title{
PENGARUH CITRA MEREK DAN PERSEPSI BIAYA PENDIDIKAN TERHADAP MINAT MELANJUTKAN STUDI
}

\section{EFFECT OF BRAND IMAGE AND PERCEPTION OF EDUCATION COSTS}

\author{
Oleh: \\ Karyati \\ Pendidikan Akuntansi Universitas Negeri Yogyakarta \\ karyati.0101@gmail.com
}

\section{Sukirno}

\author{
Staf Pengajar Jurusan P. Akuntansi Universitas Negeri Yogyakarta
}

\begin{abstract}
Abstrak
Penelitian ini bertujua untuk mengetahui Pengaruh Citra Merek (Brand Image) dan Persepsi Biaya Pendidikan terhadap Minat Melanjutkan Studi Pada Prodi Pendidikan Akuntansi FE UNY Siswa Kelas XII IPS/IIS SMA Negeri di Gunungkidul Tahun Ajaran 2015/2016. Subjek penelitian ini adalah siswa kelas XII IPS/IIS SMA Negeri di Gunungkidul Tahun Ajaran 2015/2016 sejumlah 838 siswa dan diambil sampel sebanyak 210 dengan menggunakan teknik Proporsional Area Random Sampling. Teknik pengumpulan data menggunakan dokumentasi dan kuesioner. Uji coba instrumen dilakukan di kelas XII IPS 2 SMA Negeri 2 Wonosari dengan $\mathrm{N}=30$. Uji prasyarat analisis terdiri dari uji normalitas ,uji liniearitas, uji multikolinearitas, dan uji heteroskedastisitas. Uji hipotesis terdiri dari regresi sederhana, regresi ganda, sumbangan relatif dan sumbangan efektif. Hasil penelitian ini terdapat pengaruh positif dan signifikan Citra Merek (Brand Image) dan Persepsi Biaya Pendidikan terhadap Minat Melanjutkan Studi Pada Prodi Pendidikan Akuntansi FE UNY dengan nilai $\mathbf{R}_{\mathbf{y}(1,2)}$ $=0,579 ; R_{y(1,2)}^{2}=0,335 ; \mathrm{F}_{\text {hitung }}=52,989 ; \mathrm{F}_{\text {tabel }}=3,0395 \mathrm{dan}$ nilai signifikansi 5\%. Sumbangan Relatif Citra Merek (Brand Image) sebesar 40,10\% dan Sumbangan Efektif sebesar 13,43\%. Sumbangan Relatif Persepsi Biaya Pendidikan sebesar 59,90\% dan Sumbangan Efektif sebesar 20,07\%.

Kata kunci: Citra Merek (Brand Image), Persepsi Biaya Pendidikan, Minat Melanjutkan Studi Pada Prodi Pendidikan Akuntansi FE UNY
\end{abstract}

\begin{abstract}
This research aims to know Effect of Brand Image and Perception of Education Costs to Interest of Continuing Study in Accounting Education Programs FE UNY of XII Social Class SMA Negeri in Gunungkidul Academic Year 2015/2016. Subject of this research is all student of XII Social Class SMA Negeri in Gunungkidul Academic Year 2015/2016 about 838. The research sample of 210 students were selected used was Proposional Area Random Sampling Method. Data collection was carried out questionnaries and documentation. Instrumen examination carried out in SMA Negeri 2 Wonosari with $N=30$. Test of analysis consisted of normality test, linearity test, multi-colinearity and heteroskedastisitas test. Hypothesis test was consisting of simple regression, multiple regression, relative contribution, and effective contribution. Have a positive and significant effect Brand Image and Perception of Education Costs to Interest of Continuing Study in Accounting Education Programs FE UNY by $R_{y(1,2)}=0,579 ; R_{y(1,2)}^{2}=0,335 ; F_{\text {count }}=52,989 ; F_{\text {tablel }}=3,0395$ and significanly 5\%. Relative Contribution of Brand Image amounting to $40,10 \%$ and Effective Contribution amounting to 13,43\%. Relative Contribution of Perception of Education Costs amounting to 59,90\% and Effective Contribution amounting to 20,07\%.
\end{abstract}

Keywords: Brand Image, Perception of Education Costs, Interest of Continuing Study in Accountin Education Programs FE UNY. 


\section{PENDAHULUAN}

Seiring dengan perkembangan zaman, kebutuhan manusia pun terus berkembang. Dewasa ini masyarakat mulai memasukkan kebutuhan-kebutuhan baru sebagai kebutuhan dasar mereka. Salah satu kebutuhan tersebut adalah kebutuhan akan pelayanan pendidikan. Pendidikan dianggap salah satu kebutuhan hidup yang penting dalam menunjang aktivitas sehari-hari. Apalagi ditengah perkembangan ilmu pengetahuan dan teknologi serta tuntutan globalisasi yang menginginkan manusia yang berkualitas dan profesional dan semua itu dibentuk melalui program pendidikan yang berkualitas pula.

Perkembangan teknologi informasi dapat menyebabkan konsumen menjadi seorang konsumen yang informationalised, yaitu seorang konsumen yang punya banyak pilihan (Hermawan Kartajaya, 2000). Konsumen seperti ini dapat memilih barang ataupun jasa yang akan mereka pergunakan, serta memiliki banyak kesempatan untuk membandingkan pilihan-pilihan mereka.

Perguruan tinggi merupakan salah satu lembaga penyedia jasa, yang bergerak dibidang pendidikan. Keberadaan lembaga ini sangat tergantung pada minat mahasiswa untuk masuk sebagai konsumennya. Kondisi persaingan antar lembaga pendidikan ditunjukkan dari penyedia sarana dan prasaran yang menunjang pendidikan. Seperti yang kita ketahui bahwa sekarang ini di Indonesia terdapat 1.085 Akademik, 230 Politeknik, 2.363 Sekolah Tinggi, 132 Institut, dan 516 Universitas (Sumber: Pangkatan Data Pendidikan Tinggi Direktorat Jenderal Pendidikan Tinggi).

Salah satu strategi pemasaran untuk memenangkan persaingan tersebut yaitu melalui merek. Merek merupakan hal yang sangat penting, baik bagi konsumen maupun produsen yang dalam hal ini adalah Perguruan Tinggi ataupun Program Studi. Bagi konsumen, dalam hal ini siswa SLTA (SMA), dengan adanya merek, apalagi merek tersebut mempunyai citra (image) kuat dan positif akan memudahkan siswa
SLTA (SMA) dalam memilih Perguruan Tinggi ataupun Program Studi, karena merek yang mempunyai citra positif cenderung akan lebih banyak diminati dan dipilih dibandingkan merek-merek lain yang imagenya kurang baik di mata konsumen.

Keputusan seseorang untuk menggunakan jasa merupakan suatu proses yang kompleks dan dipengaruhi oleh berbagai faktor, selain kualitas pelayanan yang diberikan, perguruan tinggi harus mempunyai kelebihan seperti menetapkan biaya pendidikan yang kompetitif. Biasanya konsumen dalam hal ini adalah calon mahasiswa dalam menggunakan layanan jasa akan membandingkan-bandingkan biaya pendidikan, memilih layanan jasa yang biaya pendidikan dasarnya rendah, memilih layanan jasa yang biaya pendidikannya sebanding dengan kualitas pelayanannya atau berbagai alasan lainnya.

Fenomena animo (peminat) pada Prodi Pendidikan Akuntansi di Fakultas Ekonomi ini cukup fluktuatif. Mengalami kenaikan pada tahun 2013 yang mencapai 2.811 dibandingkan pada tahun 2012 yaitu sebanyak 1.815. Namun, Namun pada tahun 2014 mengalami penurunan menjadi hanya 2.002 (Sumber: PMB UNY Tahun 2013, 2014 dan 2015). Penurunan ini bisa menjadi sebuah peringatan bagi pengelola untuk mengevaluasi strategi dan faktor penyebab penurunan tersebut.

Kabupaten Gunungkidul merupakan salah satu kabupaten yang ada di Provinsi DIY yang terletak di $39 \mathrm{~km}$ sebelah tenggara Kota Yogyakarta dengan jumlah penduduk 683.735 jiwa. Tingginya jumlah penduduk ternyata belum dibarengi dengan kualitasnya, diketahui angka melek huruf baru mencapai $85,22 \%$, angka rata-rata lama sekolah pun masih setara dengan kelas delapan SLTP atau baru 7,79 tahun. Selain itu, Berdasarkan Survei Sosial Ekonomi Nasional (Susenas) 2013, jenjang pendidikan tertinggi yang ditamatkan oleh penduduk usia 10 tahun ke atas di Kabupaten Gunungkidul terbesar adalah tamatan SD sederajat yaitu 33,08\% dan yang 
menduduki kursi paling rendah adalah tamatan perguruan tinggi yang hanya mencapai 3,65\% (Sumber: RKPD Kabupaten Gunungkidul Tahun 2016). Padalah jumlah sekolah yang ada juga tidak sedikit khususnya untuk SMA yang terdiri atas 12 SMA Negeri dan 13 SMA Swasta dengan total siswa pada tahun 2016 sebayak 1.358. Untuk memutuskan melanjutkan studi ke perguruan tinggi sendiri banyak faktor seperti tingkat ekonomi orang tua, faktor budaya dimana warga masih beranggapan bahwa anak perempuan tidak perlu sekolah tinggi dan lain yang berasal dari diri siswa itu sendiri.

Berdasarkan latar belakang masalah di atas maka peneliti ingin meneliti bagaimana pengaruh Citra Merek dan Biaya Penddikan terhadap Minat Melanjutkan Studi. Oleh karena itu peneliti tertarik untuk melakukan penelitian dengan judul "Pengaruh Citra Merek (Brand Image) dan Persepsi Biaya Pendidikan terhadap Minat Melanjutkan Studi Pada Prodi Pendidikan Akuntansi FE UNY Siswa Kelas XII IPS/IIS SMA Negeri di Gunungkidul Tahun Ajaran 2015/2016".

\section{METODE PENELITIAN}

Penelitian ini merupakan penelitian ex post facto karena data yang diperoleh dari peristiwa yang sudah berlangsung, sehingga peneliti hanya mengungkap fakta berdasarkan pengukuran gejala yang telah ada pada responden (Suharsimi Arikunto, 2010:17). Penelitian ini dimaksudkan untuk mencari hubungan atau pengaruh antara dua variabel atau lebih pada suatu waktu tertentu. Populasi penelitian ini adalah siswa kelas XII IPS/IIS SMA Negeri di Gunungkidul. Teknik pengambilan sampel untuk penelitian ini adalah Proporsional Area Radom Sampling. Jumlah sampel yang diambil adalah sebanyak 21 siswa atau $25 \%$ dari populasi sejumlah 838 siswa. Penelitian ini menggunakan dokumentasi dan kuesioner (angket) sebagai instrumen pengumpulan data. Kuesioner dibuat untuk mengetahui Citra Merek (Brand Image),
Persepsi Biaya Pendidikan dan Minat Melanjutkan Studi Pada Prodi Pendidikan Akuntansi FE UNY dikalangan siswa kelas XII IPS/IIS SMA Negeri di Gunungkidul. Skala Likert 4 tingkat digunakan dalam pengukuran. Uji Validitas dan Reliabilitas dilakukan sebelum kuesioner disebarkan kepada responden. Penelitian ini dilaksanakan pada bulan Januari-Februari 2016 di 11 SMA Negeri di Gunungkidul.

Penelitian ini menggunakan analisis data statistik deskriptif dan regresi berganda atau inferensial serta menghitung Sumbangan Relatif dan Sumbangan Efektif. Fokus kajian analisis statistik inferensial ini ada pada masalah analisis dan interpretasi data untuk menarik kesimpulan. Tujuan analisis ini adalah untuk menguji pengaruh variabel bebas terhadap variabel terikatnya, secara parsial maupun simultan/bersamasama. Data harus lolos uji asumsi klasik (uji prasyarat analisis) terlebih dahulu sebelum menggunakan teknik analisis regresi berganda. Macam uji asumsi klasik yang digunakan adalah Uji Normalitas, Uji Liniearitas, Uji Multikolinearitas, dan Uji Heteroskedastisitas. Pengujian dan analisis hipotesis dilakukan dengan Uji t dan Uji F. Tingkat signifikansi yang dipergunakan dalam penelitian ini $5 \%(\alpha=0,05)$. Analisis data menggunakan bantuan program SPSS Statistics. Perhitungan Sumbangan Relatif dimaksudkan untuk mengetahui seberapa besarnya sumbangan secara relatif setiap prediktor terhadap kriteria untuk keperluan prediksi, sedangkan Sumbangan Efektif bertujuan untuk mengetahui besarnya sumbangan efektif setiap prediktor terhadap kriterium dengan tetap memperhitungkan variabel lain yang tidak diteliti.

\section{HASIL PENELITIAN DAN PEMBA- HASAN}

\section{Analisis Deskriptif}

a. Minat Melanjutkan Studi Pada Prodi Pendidikan Akuntansi FE UNY

Data variabel Minat Melanjutkan Studi Pada Prodi Pendidikan Akuntansi FE UNY diperoleh melalui angket yang terdiri dari 20 
item pernyataan dengan jumlah responden sebanyak 210 siswa. Berdasarkan analisis data variabel Minat Melanjutkan Studi Pada Prodi Pendidikan Akuntansi FE UNY dengan menggunakan bantuan komputer program SPSS Statistics diperoleh skor tertinggi 75 dan skor terendah 26, dengan nilai mean sebesar 54,28 , median sebesar 55,00 , modus sebesar 58,00 dan standar deviasi sebesar 8,657. Adapun distribusi frekuensi Minat Melanjutkan Studi Pada Prodi Pendidikan Akuntansi FE UNY dapat dilihat pada tabel berikut ini:

Tabel 1. Distribusi Frekuensi Data Variabel Minat Melanjutkan Studi Pada Prodi Pendidikan Akuntansi FE UNY

\begin{tabular}{|c|c|c|c|}
\hline No. & Kelas Interval & $\mathbf{F}$ & $\%$ \\
\hline 1 & $25-30$ & 1 & 0,48 \\
\hline 2 & $31-36$ & 3 & 1,43 \\
\hline 3 & $37-42$ & 17 & 8,10 \\
\hline 4 & $43-48$ & 35 & 16,67 \\
\hline 5 & $49-54$ & 41 & 19,52 \\
\hline 6 & $55-60$ & 67 & 31,90 \\
\hline 7 & $61-66$ & 30 & 14,29 \\
\hline 8 & $67-72$ & 13 & 6,19 \\
\hline 9 & $73-78$ & 3 & 1,43 \\
\hline \multicolumn{2}{|c|}{ Jumlah } & 210 & 100 \\
\hline
\end{tabular}

Sumber: Data primer yang sudah diolah

Berdasarkan tabel distribusi frekuensi tersebut, dapat digambarkan dalam histogram sebagai berikut:

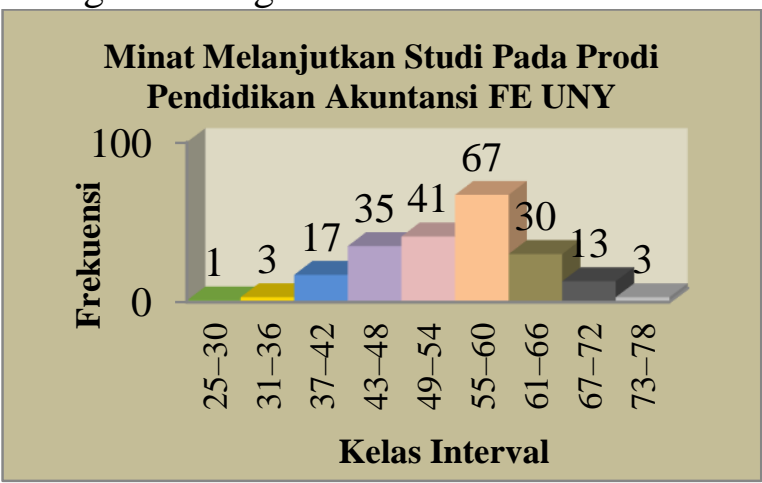

Gambar 1. Histogram

Distribusi

Frekuensi

Minat

Melanjutkan Studi Pada

Prodi Pendidikan Akuntansi FE UNY.
Berdasarkan data di atas, dapat dibuat kategori kecenderungan sebagai berikut:

Tabel 2.Kategori Kecenderungan Minat Melanjutkan Studi Pada Prodi Pendidikan Akuntansi FE UNY

\begin{tabular}{|c|c|c|c|c|}
\hline No. & Skor & F & \% & Kat. \\
\hline 1. & $>58,67$ & 68 & 32,38 & ST \\
\hline 2. & $42,33-58,67$ & 121 & 57,62 & S \\
\hline 3. & $<42,33$ & 21 & 10 & R \\
\hline & Jumlah & 210 & 100 & \\
\hline
\end{tabular}

Sumber: Data primer yang sudah diolah

Tabel di atas menunjukkan bahwa terdapat kategori sangat tinggi sebesar 68 $(32,38 \%)$, kategori sedang sebesar 121 $(57,62 \%)$, dan kategori rendah sebesar 21 $(10 \%)$.

Kecenderungan variabel Minat Melanjutkan Studi Pada Prodi Pendidikan Akuntansi FE UNY dapat disajikan dalam Pie Chart sebagai berikut:

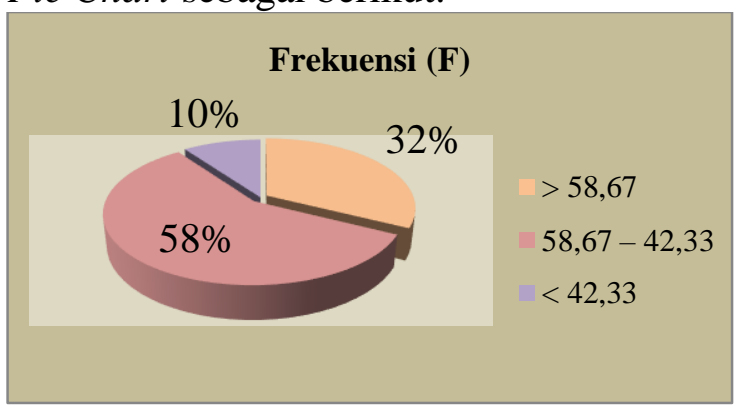

Gambar 2.Pie Chart Kecenderungan Minat Melanjutkan Studi Pada Prodi Pendidikan Akuntansi FE UNY

Dapat disimpulkan bahwa variabel Minat Melanjutkan Studi Pada Prodi Pendidikan Akuntansi FE UNY termasuk dalam kategori Sedang sebesar 57,62\%.

\section{b. Citra Merek (Brand Image)}

Data variabel Citra Merek (Brand Image) diperoleh melalui angket yang terdiri dari 19 item pernyataan dengan jumlah responden sebanyak 210 siswa. Berdasarkan analisis data variabel Citra Merek (Brand Image) dengan menggunakan SPSS Statistics , maka dapat diperoleh skor tertinggi 74 dan skor terendah 25; dengan nilai Mean sebesar 
56,68, Median sebesar 57,00, Modus sebesar 57,00 dan Standar Deviasi sebesar 6,289.

Tabel 3. Distrisbusi Frekuensi Citra Merek (Brand Image)

\begin{tabular}{|c|c|c|c|}
\hline No. & Interval & F & \% \\
\hline 1. & $25-30$ & 1 & 0,48 \\
\hline 2. & $31-36$ & 1 & 0,95 \\
\hline 3. & $37-42$ & 2 & 0,95 \\
\hline 4. & $43-48$ & 14 & 4,76 \\
\hline 5. & $49-54$ & 39 & 19,52 \\
\hline 6. & $55-60$ & 104 & 48,57 \\
\hline 7. & $61-66$ & 38 & 18,10 \\
\hline 8. & $67-72$ & 10 & 5,71 \\
\hline 9. & $73-78$ & 1 & 0,95 \\
\hline \multicolumn{2}{|c|}{ Jumlah } & 210 & 100 \\
\hline
\end{tabular}

Berdasarkan tabel Distribusi Frekuensi

Citra Merek (Brand Image) dapat digambarkan dalam Histogram sebagai berikut:

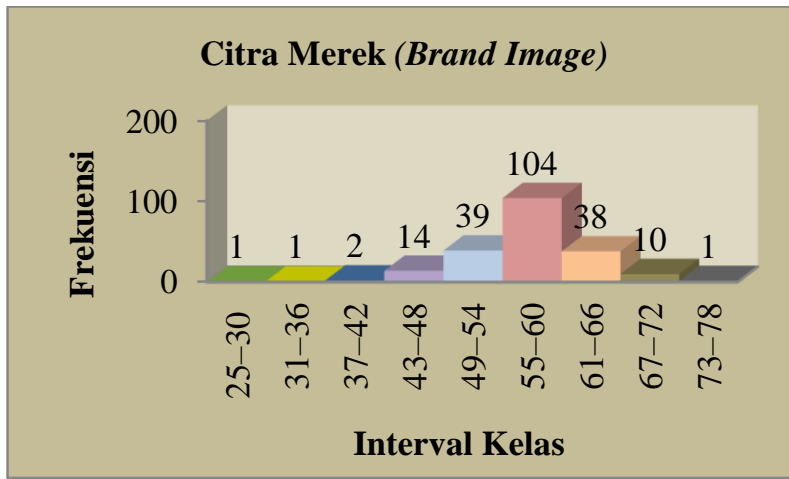

\section{Gambar 3. Histogram Distribusi Frekuensi Citra Merek (Brand Image)}

Berdasarkan perhitungan di atas, maka diperoleh kriteria kecenderungan Citra Merek (Brand Image) sebagai berikut:

Tabel 4. Kategori Kecenderungan Citra Merek (Brand Image)

\begin{tabular}{|c|c|c|c|c|}
\hline No. & Skor & F & \% & Kat. \\
\hline 1. & $>57,67$ & 95 & 45,24 & ST \\
\hline 2. & $41,33-57,67$ & 100 & 47,62 & S \\
\hline 3. & $<41,33$ & 15 & 7,14 & R \\
\hline & Jumlah & 210 & 100 & \\
\hline
\end{tabular}

Tabel di atas menunjukkan bahwa terdapat kategori sangat tinggi sebesar 95 (45,24\%), kategori sedang sebesar 100
$(47,62 \%)$, dan kategori rendah sebesar 15 $(7,14 \%)$.

Berdasarkan distribusi kecenderungan frekuensi variabel Citra Merek (Brand Image) di atas dapat digambarkan dalam Pie Chart sebagai berikut:

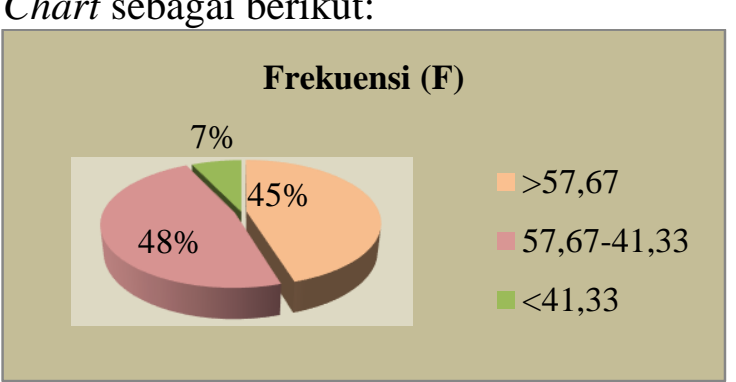

\section{Gambar 4.Pie Chart Kecenderungan}

Citra Merek (Brand Image)

Dapat disimpulkan bahwa variabel Citra Merek (Brand Image) termasuk dalam kategori Sedang sebesar 47,62\%.

c. Persepsi Biaya Pendidikan

Berdasarkan analisis data variabel Persepsi Biaya Pendidikan dengan menggunakan SPSS Statistics, maka dapat diperoleh skor tertinggi 16 dan skor terendah 9, dengan nilai Mean sebesar 12,21; Median sebesar 12,00; Modus sebesar 12,00 dan Standar Deviasi sebesar 1,228.

Tabel 5. Distribusi Frekuensi Persepsi Biaya Pendidikan

\begin{tabular}{|c|c|c|c|}
\hline No. & Interval & Frekuensi & $\%$ \\
\hline 1. & $4-5$ & 0 & 0 \\
\hline 2. & $6-7$ & 0 & 0,48 \\
\hline 3. & $8-9$ & 5 & 0,95 \\
\hline 4. & $10-11$ & 49 & 13,33 \\
\hline 5. & $12-13$ & 127 & 52,38 \\
\hline 6. & 14-15 & 29 & 30,95 \\
\hline 7. & 16-17 & 0 & 1,90 \\
\hline 8. & 18-19 & 0 & 0 \\
\hline 9. & $20-21$ & 0 & 0 \\
\hline \multicolumn{2}{|c|}{ Jumlah } & 210 & 100 \\
\hline
\end{tabular}

Sumber: Data Primer yang telah diolah

Berdasarkan tabel Distribusi Frekuensi Persepsi Biaya Pendidikan dapat digambarkan Histogram sebagai berikut: 


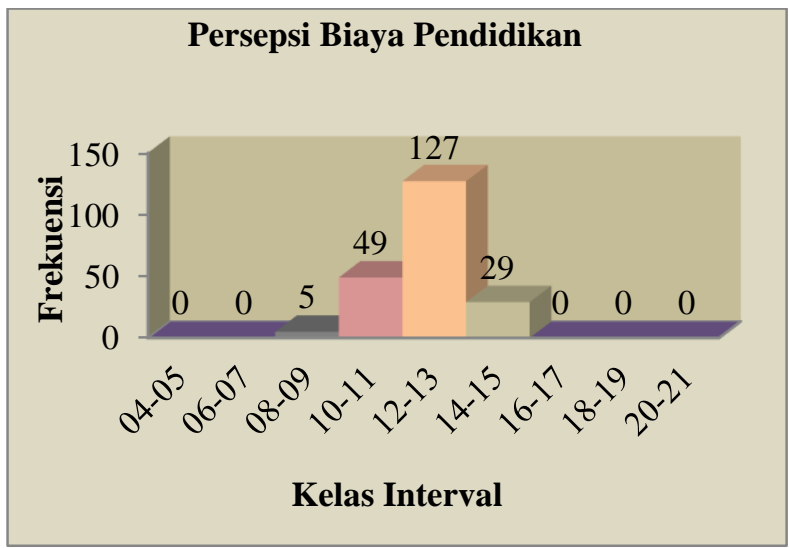

Gambar 5. Histogram Distribusi Frekuensi Persepsi Biaya Pendidikan

Berdasarkan perhitungan di atas, maka diperoleh kriteria kecenderungan Persepsi Biaya Pendidikan sebagai berikut:

Tabel 6. Kategori Kecenderungan Persepsi Biaya Pendidikan

\begin{tabular}{|c|c|c|c|c|}
\hline No. & Skor & F & \% & Kat. \\
\hline 1. & $>13$ & 29 & 13,81 & ST \\
\hline 2. & $11-13$ & 163 & 77,62 & S \\
\hline 3. & $<11$ & 18 & 8,57 & R \\
\hline \multicolumn{2}{|r|}{ Jumlah } & 210 & 100 & \\
\hline
\end{tabular}

Tabel di atas menunjukkan bahwa terdapat kategori sangat tinggi sebesar 29 $(13,81 \%)$, kategori sedang sebesar 163 $(77,62 \%)$, dan kategori rendah sebesar 18 $(8,57 \%)$.

Berdasarkan distribusi kecenderungan frekuensi variabel Persepsi Biaya Pendidikan di atas dapat di gambarkan dalam Pie Chart sebagai berikut:

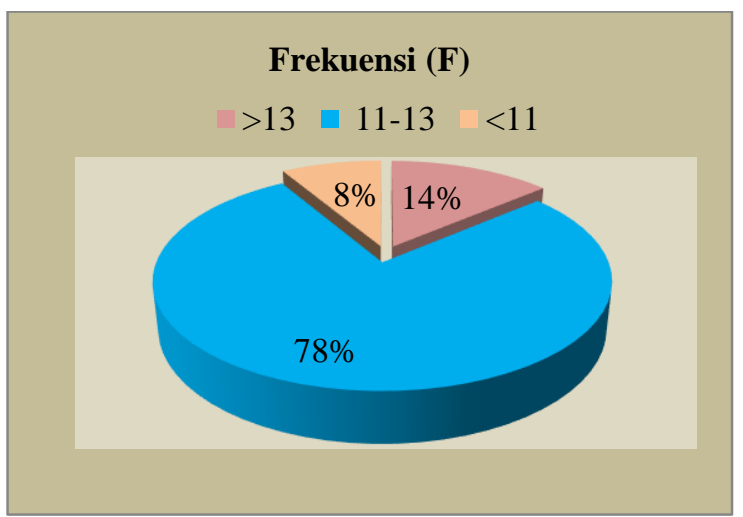

Gambar 6. Pie Chart Kecenderungan Persepsi Biaya Pendidikan
Dapat disimpulkan bahwa variabel Persepsi Biaya Pendidikan termasuk dalam kategori Sedang sebesar 77,62\%.

\section{Uji Hipotesis}

Tabel 7.Hasil Pengujian Hipotesis Pertama dan Kedua

\begin{tabular}{|l|l|l|}
\hline \multicolumn{1}{|c|}{ Model* } & \multicolumn{1}{c|}{$\mathbf{X}_{\mathbf{1}}$} & \multicolumn{1}{c|}{$\mathbf{X}_{\mathbf{2}}$} \\
\hline Koefisien & 0,796 & $-0,759$ \\
\hline Konstanta & 9,169 & 63,550 \\
\hline $\mathrm{r}_{\mathrm{x} 1 \mathrm{y}}$ & 0,578 & 0,108 \\
\hline $\mathrm{r}^{2}{ }_{\mathrm{x} 1 \mathrm{y}}$ & 0,334 & 0,012 \\
\hline $\mathrm{t}_{\text {hitung }}$ & 10,211 & $-1,563$ \\
\hline $\mathrm{t}_{\text {tabel }}$ & 1,97149 & 1,97149 \\
\hline $\mathrm{P}$ & 0,000 & 0,120 \\
\hline Keterangan & $\begin{array}{l}\text { Positif dan } \\
\text { Signifikan }\end{array}$ & $\begin{array}{l}\text { Negatif dan } \\
\text { Tidak } \\
\text { Signifikan }\end{array}$ \\
\hline
\end{tabular}

*) Variabel terikat: Minat Melanjutkan Studi Pada Prodi Pendidikan Akuntansi FE UNY.

Tabel 7 menunjukkan hasil uji regresi secara partial variabel Citra Merek (Brand Image) $\left(\mathrm{X}_{1}\right)$ dan Persepsi Biaya Pendidikan $\left(\mathrm{X}_{2}\right)$ terhadap Minat Melanjutkan Studi Pada Prodi Pendidikan Akuntansi FE UNY (Y). Dari tabel tersebut, untuk variabel Citra Merek (Brand Image) ( $\left.\mathrm{X}_{1}\right)$ hasilnya menunjukkan bahwa harga $\mathrm{r}_{\mathrm{x} 1 \mathrm{y}}$ sebesar 0,578 dan $r^{2}{ }_{x 1 y}$ sebesar 0,334. Selain itu juga diperoleh harga $t_{\text {hitung }} 10,211$ yang lebih besar dari harga $t_{\text {tabel }}$ yaitu 1,97149 dengan tingkat signifikansi atau probabilitas 0,000. Nilai signifikansi tersebut lebih kecil dari 0,05 .

Berdasarkan hasil pengujian hipotesis pertama yang telah dilakukan menunjukkan bahwa $\mathrm{Ha}_{1}$ diterima secara parsial. Dimana variabel Citra Merek (Brand Image) berpengaruh terhadap Minat Melanjutkan Studi Pada Prodi Pendidikan Akuntansi FE UNY diterima dengan arah positif. Responden menganggap bahwa semakin baik atau tinggi citra suatu program studi dalam hal ini adalah Prodi Pendidikan Akuntansi maka akan meningkat pula minat melanjutkan studi pada prodi tersebut.

Hasil penelitian ini pun selaras dengan penelitian dari Ike Mety Wulandari (2013) yang berjudul "Pengaruh Brand Image dan 
Lokasi terhadap Keputusan Calon Mahasiswa Melanjutkan Studi di Perguruan Tinggi (Studi Kasus pada Siswa Kelas XII SMAN Jurusan IPS di Kota Jember)". Selain itu, didukung dengan teori dari Buchari Alma dan Ratih Hurriyati (2009:57) yaitu "ketika perguruan tinggi mampu menciptakan image positif, maka masyarakat dapat membuat keputusan untuk mendaftarkan putra-putri mereka masuk perguruan tinggi yang bersangkutan".

Variabel kedua dalam pengujian hipotesis secara parsial yaitu Persepsi Biaya Pendidikan $\left(\mathrm{X}_{2}\right)$. Dari tabel di atas, hasilnya menunjukkan bahwa harga $\mathbf{r}_{\mathrm{x} 2 \mathrm{y}}$ sebesar 0,108 dan $r^{2} x 2 y$ sebesar 0,012. Selain itu, juga diperoleh harga thitung $-1,563$ yang lebih kecil daripada harga tabel yaitu 1,97149 dengan tingkat signifikansi atau probabilitas 0,120 . Nilai signifikansi tersebut lebih besar dari 0,05 .

Berdasarkan hasil pengujian hipotesis kedua yang telah dilakukan menunjukkan bahwa Persepsi Biaya Pendidikan berpengaruh terhadap Minat Melanjutkan Studi Pada Prodi Pendidikan Akuntansi FE UNY dengan arah negatif, namun tidak cukup signifikan pada tingkat probabilitas $95 \%(0,120>0,05)$. Responden beranggapan bahwa ketika terjadi kenaikan pada biaya pendidikan, justru akan menurunkan minta untuk melanjutkan studi, dalam hal ini pada Prodi Pendidikan Akuntansi FE UNY.

Hasil penelitian ini mendukung pendapat yang dikemukakan oleh Agung Bawantara (2007: 5) yaitu, "Ada 3 (tiga) pertimbangan dalam memilih program studi yaitu berdasarkan minat dan bakat, disesuaikan dengan kemampuan intelektual serta diselaraskan dengan kemampuan finansial keluarga". Berkaitan dengan pertimbangan ke 3 yaitu diselaraskan dengan kemampuan finansial keluarga, berdasarkan data yang terkumpul diketahui bahwa mayoritas penghasilan keluarga masih dibawah Rp1.000.000,00 dan Ayah responden bekerja sebagai petani. Sehingga responden sensitif terhadap perubahan tingkat biaya pendidikan apalagi perubahan yang mengarah pada kenaikan biaya pendidikan.

Hasil penelitian ini juga tidak mendukung penelitian yang dilakukan oleh Karina Pradityas Putri (2011) yang berjudul "Analisis Pengaruh Brand Image, Biaya Pendidikan, dan Fasilitas Pendidikan Terhadap Keputusan Mahasiswa Melanjutkan Studi Pada Program Diploma III Fakultas Ekonomi Universitas Diponegoro Semarang". Dimana variabel biaya pendidikan $\left(\mathrm{X}_{2}\right)$ memiliki nilai koefisien sebesar 0,107 (bertanda positif) dengan tingkat signifikansi $0,031(<0,05)$.

Selanjutnya untuk pengujian hipotesis ketiga hasilnya sebagai berikut:

Tabel 8. Hasil Pengujian Hipotesis Ketiga

\begin{tabular}{|l|l|l|l|}
\hline Model* & Konstanta & $\mathbf{X}_{\mathbf{1}}$ & $\mathbf{X}_{\mathbf{2}}$ \\
\hline Koefisien & 5,153 & 0,809 & 0,268 \\
\hline $\mathrm{R}_{\mathrm{y}(1,2)}$ & & \multicolumn{2}{|c|}{0,579} \\
\hline $\mathrm{R}^{2}{ }_{\mathrm{y}(1,2)}$ & & 0,335 \\
\hline $\mathrm{F}_{\text {hitung }}$ & & \multicolumn{2}{|c|}{52,202} \\
\hline $\mathrm{F}_{\text {tabel }}$ & & \multicolumn{2}{|c|}{3,0395} \\
\hline $\mathrm{P}$ & \multicolumn{3}{|c|}{0,000} \\
\hline Keterangan & \multicolumn{2}{|c|}{ Positif dan Signifikan } \\
\hline
\end{tabular}

Tabel 8 menunjukkan hasil uji regresi ganda variabel Citra Merek (Brand Image) $\left(\mathrm{X}_{1}\right)$ dan Persepsi Biaya Pendidikan $\left(\mathrm{X}_{2}\right)$ terhadap Minat Melanjutkan Studi Pada Prodi Pendidikan Akuntansi FE UNY (Y). Dari tabel tersebut, $\mathrm{R}_{\mathrm{y}(1,2)}$ sebesar 0,579; $\mathrm{R}_{\mathrm{y}(1,2)}^{2}$ sebesar 0,335. Selain itu， juga diperoleh harga $F_{\text {hitung }} 52,202$ yang lebih besar daripada $\mathrm{F}_{\text {tabel }}$ 3,0395 dengan tingkat signifikansi atau probabilitas 0,000 . Nilai signifikasi tersebut lebih kecil dari 0,05. Hal ini menandakan bahwa Citra Merek (Brand Image) dan Persepsi Biaya Pendidikan secara simultan berpengaruh terhadap Minat Melanjutkan Studi Pada Prodi Pendidikan Akuntansi FE UNY dengan arah positif. Sehingga dapat disimpulkan bahwa Ho ditolak dan Ha diterima 
Tabel 9. Ringkasan Hasil Perhitungan Sumbangan Relatif dan Sumbangan Efektif

\begin{tabular}{|l|c|c|}
\hline \multirow{2}{*}{ Variabel } & \multicolumn{2}{|c|}{ Sumbangan } \\
\cline { 2 - 3 } & Relatif (\%) & Efektif (\%) \\
\hline $\mathrm{X}_{1}$ & $40,10 \%$ & $13,43 \%$ \\
\hline $\mathrm{X}_{2}$ & $59,90 \%$ & $20,07 \%$ \\
\hline Total & $100 \%$ & $33,5 \%$ \\
\hline
\end{tabular}

Berdasarkan hasil perhitungan Sumbangan Relatif dan Sumbangan Efektif diketahui variabel Citra Merek (Brand Image) dan Persepsi Biaya Pendidikan Sumbangan Efektif sebesar $33,5 \%$ sedangkan $66,5 \%$ diberikan oleh variabelvariabel lain yang tidak diteliti dan dibahas dalam penelitian ini

\section{SIMPULAN DAN SARAN Simpulan}

Terdapat pengaruh positif dan signifikan Citra Merek (Brand Image) dan Persepsi Biaya Pendidikan terhadap Minat Melanjutkan Studi Pada Prodi Pendidikan Akuntansi FE UNY Siswa Kelas XII IPS/IIS SMA Negeri di Gunungkidul Tahun Ajaran $2015 / 2016$, dengan $R_{y(1,2)}=0,579 ; R_{y(1,2)}^{2}=$ 0,$335 ; \mathrm{F}_{\text {hitung }} 52,202 ; \mathrm{F}_{\text {tabel }} ;$ Kostanta $=$ 5,153 ; koefisien $\mathrm{X}_{1}=0,809$, koefisien $\mathrm{X}_{2}=$ 0,268 dengan taraf signifikansi $5 \%$. Sumbangan Efektif diketahui variabel Citra Merek (Brand Image) dan Persepsi Biaya Pendidikan Sumbangan Efektif sebesar $33,5 \%$ sedangkan $66,5 \%$ diberikan oleh variabel-variabel lain yang tidak diteliti dan dibahas dalam penelitian ini.

\section{Saran}

Bagi pihak pengelola Prodi Pendidikan Akuntansi FE UNY

\begin{tabular}{lcr}
\multicolumn{2}{c}{ Perlunya untuk } & meningkatkan \\
promosi & dengan & memaksimalkan \\
penggunaan & Public & Relation, berupa \\
publikasi, & kegiatan, dan Comunity
\end{tabular} Involvement serta Social Investment dengan melibatkan mahasiswa berprestasi dan mahasiswa yang mampu kuliah walaupun dari keluarga kurang mampu di berbagai kegiatan seperti LCCA, KKN/PPL serta bisa bekerjasama dengan pihak-pihak sekolah untuk melakukan sosialisasi kepada siswa secara langsung.

Bagi penelitian selanjutnya.

Diharapkan dapat mengembangkan metode pengambilan sampel dan teknik pengumpulan data dengan menambahkan wawancara, serta memperluas jangkauan penelitian dengan menggunakan faktorfaktor lain, berdasar pada nilai sumbangan efektif 2 variabel dalam penelitian ini hanya $33,5 \%$, terdapat $66,5 \%$ dipengaruhi oleh variabel-variabel lain yang tidak diteliti pada penelitian ini.

\section{DAFTAR PUSTAKA}

Agung Bawantara. (2007). Lulus SMA Kuliah Dimana? Panduan Memilih Program Studi. Jakarta: PT. Kawan Pustaka.

Buchari Alma \& Ratih Hurriyanti. (2009). Manajemen Corporate dan Strategi Pemasaran Jasa Pendidikan Fokus pada Mutu dan Layanan Prima. Bandung: Alfabeta.

Hermawan Kertajaya. (2000). Marketing Plus 2000 Siasat Memenangkan Persaingan Global. Jakarta: Gramedia Pustaka Utama.

Ike Mety Wulandari. (2013). Pengaruh Brand Image dan Lokasi Terhadap Keputusan Calon Mahasiswa Melanjutkan Studi Di Perguruan Tinggi (Studi Kasus Pada Siswa Kelas XII SMAN Jurusan IPS DI Kota Jember). Skripsi. Universitas Jember.

Karina Pradityas Putri. (2011). Analisis Pengaruh Brand Image, Biaya Pendidikan, Dan Fasilitas Pendidikan Terhadap Keputusan Mahasiswa Melanjutkan Studi Pada Program Diploma II Fakultas Ekonomi Universitas Diponegoro Semarang. Skripsi. Universitas Diponegoro.

PDDIKTI. (2013). Grafik Jumlah Perguruan Tinggi.

(http://forlap.dikti.go.id/perguruanting 
gi/homegraphpt) . Diakses pada 17 September 2015.

Pemerintahan Kabupaten Gunungkidul. (2015). Rencana Kerja Pembangunan Daerah Kabupaten Gunungkidul Tahun 2016. (http://bappeda.gunungkidulkab.go.id/ publikasi/rkpd). Diunduh pada 12 Desember 2015.

Suharsimi Arikunto. (2010). Prosedur Penelitian. Jakarta: Rineka Cipta.

Tim Penyusun. (2014). PMB UNY 2014. Diakses pada anggal 20 Desember 2015

http://pmb2014.uny.ac.id/sites/pmb201 4.uny.ac.id/files/leaflet-pmb-uny2014.pdf.

UNY. (2015). Pengumuman. Diakses pada 20 Desember 2015 dari http://pmb.uny.ac.id/snmptn/pengumu man.pdf.

UNY Comunity. (2015). PMB UNY 2015. Diakses pada 10 September 2015 dari http://unycommunity.com/pmb-uny2015/. 